\title{
Monitoring of Soybean Oil Transesterification by Spectrofluorimetry and Multivariate Calibration
}

\author{
Erika Maria de Oliveira Ribeiro ${ }^{1 *}$, Cristina Maria Quintella1, Marilena Meira ${ }^{2}$, \\ Saionara Luna1, Alexandre Kamei Guimarães ${ }^{1}$, Weidson Leal Silva1 \\ ${ }^{1}$ Instituto de Química, Universidade Federal da Bahia, Campus de Ondina, Salvador, Brasil \\ ${ }^{2}$ Instituto de Educação, Ciência e Tecnologia da Bahia, Campus de Simões Filho, Brasil \\ Email: ${ }^{*}$ erikaribeiro08@gmail.com
}

Received 9 April 2014; revised 16 May 2014; accepted 22 June 2014

Copyright (C) 2014 by authors and OALib.

This work is licensed under the Creative Commons Attribution International License (CC BY). http://creativecommons.org/licenses/by/4.0/

(c) (i) Open Access

\begin{abstract}
An analytical procedure was developed to monitor the transesterification of soybean oil using spectrofluorimetry and Partial Least Squares (PLS) regression. Excitation-Emission Matrix (EEM) fluorescence spectroscopy derived from 12 standard mixtures of triolein and ethyl oleate were used in the construction of a PLS model using the fluorescent spectra as independent variables and the values of the methyl oleate $\%(w / w)$ as dependent variables. The model presented a high correlation (0.99178) between values determined by the reference method (ATR-FTIR) and values predicted by the proposed method. The coefficient of determination $\left(R^{2}\right)$ for the curve was close to a value of $1(0.9836)$, which indicated the strength in the association between the observed data for the two variables and the efficiency of the model to perform the analysis. Therefore, the association between spectrofluorimetry and PLS was shown to be a fast and accurate method for monitoring soybean oil transesterification.
\end{abstract}

\section{Keywords}

Soybean Oil, Transesterification, Spectrofluorimetry, PLS

Subject Areas: Analytical Chemistry, Petrochemistry

\section{Introduction}

The production of biodiesel from renewable lipid sources was the result of a global environmental preoccupation.

${ }^{*}$ Corresponding author.

How to cite this paper: de Oliveira Ribeiro, E.M., Quintella, C.M., Meira, M., Luna, S., Guimarães, A.K. and Silva, W.L. (2014) Monitoring of Soybean Oil Transesterification by Spectrofluorimetry and Multivariate Calibration. Open Access Library Journal, 1: e598. http://dx.doi.org/10.4236/oalib.1100598 
This tendency led the Brazilian Government to establish the national pro-biodiesel program, and to evaluate the technical and environmental advantages of biodiesel in relation to diesel oil [1]. The studies have shown that biodiesel is an option as a substitute for fuels derived from petroleum because it has technical properties similar to diesel, as well as economic, environmental and social impacts.

The most frequently used process for the production of biodiesel is transesterification, which turns the oils into esters. Transesterification consists of the reaction of triglycerides, the main components of fats and oils, with short chain alcohols, such as methanol and ethanol [2]. In other words, transesterification proceeds via the ethylic route (ethanolysis) or via the methyl route (methanolysis), both resulting in many benefits relating to the respective vegetable oil: reduction of density and viscosity; fitting within the specification of diesel oil; decrease in the point of loom and cloud point; reduction in the residue of carbon values less than diesel; giving rise to products with a lower molecular weight [3].

Although transesterification is currently the best alternative, it still needs to be optimized, because some factors influence this reaction, such as catalyst type, alcohol type, molar alcohol/oil ratio, temperature, purity of the reagents, presence of water and amount of free fatty acids [4]. Several methods have been used to evaluate the quality of the process for biodiesel production, such as gas chromatography (GC) [5], high-performance liquid chromatography (HPLC) [6] and nuclear magnetic resonance (NMR) [7]. Furthermore, a Viscometer [8], Near Infrared Spectroscopy (NIR) and a multivariate approach [9], Fourier-Transformed Infrared (FTIR) Spectroscopy [1], Size Exclusion Chromatography (SEC) [10], Ultrasonic Measurement [11] and Fiber-Optic Near Infrared Spectroscopy with Correlation to $1 \mathrm{H}$ Nuclear Magnetic Resonance Spectroscopy NMR [12] are some of the many analytical procedures developed to determine the composition of reaction mixtures during transesterification.

The spectrofluorimetry is an analytical technique with attractive advantages because of its simplicity, rapidity, sensitivity, and selectivity. This technique, together with multivariate analysis (PCA), was used to identify the addition of nontransesterified residual vegetable oil, instead of biodiesel, to diesel oil.

Also, spectrofluorimetry associated with Partial Least Square (PLS) has been used to determine the oxidation stability, concentration, viscosity and specific gravity of biodiesel-diesel blends [13]. A method and a device sensor were developed to monitor the quality in process for the production of fuels using spectrofluorimetry total 3D and PCA [14]. In this work, an analytical procedure was developed to monitor the transesterification of soybean oil using spectrofluorimetry and Partial Least Squares (PLS) regression for the optimization of biodiesel production.

\section{Experimental Section}

\subsection{Sample}

Samples of soybean oil (mark: Bompreço ${ }^{\circledR}$; date of production: 19/04/2013 and validity: 13/01/2014) were transesterified at different times of reaction.

Standard mixtures of triolein (mark: Sigma Aldrich) and ethyl oleate (mark: Sigma Aldrich) in different concentrations were prepared (Table 1).

\subsection{Procedure for Transesterification}

The transesterification reaction was carried out using $450 \mathrm{ml}$ of soybean oil. The reaction was catalyzed using potassium hydroxide $(2.25 \mathrm{~g})$ in methanol $(360 \mathrm{~mL})$. The reaction mixture was maintained under agitation (90 $\mathrm{rpm}$ ) at $40^{\circ} \mathrm{C}$ (in a water bath for temperature control). Aliquots of $40 \mathrm{~mL}$ after $0,5,10,15,20,25,30,35,40,45$, 50, 55 and 60 minutes were collected and immediately treated with $20 \mathrm{ml}$ of an aqueous solution of ammonium chloride $(20 \% \mathrm{w} / \mathrm{v})$. These were centrifuged and the upper phase was washed with $125 \mathrm{~mL}$ of deionized water to achieve a pH of 7.0. For drying the residue in water samples, $5 \mathrm{~g}$ of anhydrous sodium sulfate was used.

\subsection{Spectrofluorimetry}

In this work, a Perkin Elmer-LS55 spectrofluorometer equipped with a $150 \mathrm{~W}$ Xenon lamp and quartz cells with $1 \mathrm{~cm}$ of optical path was used. The excitation was initiated at $200 \mathrm{~nm}$ with increments of $25 \mathrm{~nm}$ and the emission in the range of $230-800 \mathrm{~nm}$ with increments of $0.5 \mathrm{~nm}$. Excitation and emission slits were of $2.5 \mathrm{~nm}$, and the scan speed was $1200 \mathrm{~nm} \cdot \mathrm{min}^{-1}$. For each sample 24 emission spectra were obtained. The spectrofluorimetric 
Table 1. Standard mixtures used in the PLS models.

\begin{tabular}{ccc}
\hline Methyl oleate $\mathbf{( \% )}(\mathbf{m} / \mathbf{m})$ & Triolein (\%) \\
\hline 0 & 100 \\
19.662475182 & 90.33752482 \\
29.20649033 & 80.60230292 \\
39.0896921 & 70.79350967 \\
49.0481523 & 60.9103079 \\
59.08273381 & 50.9518477 \\
69.1943128 & 40.91726619 \\
79.38377889 & 30.8056872 \\
89.65203548 & 20.61622111 \\
100 & 10.34796452 \\
\hline
\end{tabular}

maps were generated with the aid of Origin $8.0^{\circledR}$. This procedure was according to Meira et al. [15].

\subsection{Fourier-Transformed Infrared Spectroscopy (FTIR/ATR)}

Infrared spectra of the samples and standards were acquired using a Perkin Elmer spectrophotometer, Frontier model, with ZnSe crystal. The wave number used was in the region of $4000-650 \mathrm{~cm}^{-1}$. Each spectrum MIR was recorded on an average spectrum resulting from 16 scans, employing a resolution of $4 \mathrm{~cm}^{-1}$.

\subsection{Multivariate Analysis}

Fluorescence spectra of the transesterified samples and the ATR/FTIR spectra of mixtures of 12 standards of triolein (representing triglycerides found in vegetable oils) and ethyl oleate (representing ethyl esters produced as a result of transesterification) at different concentrations (Table 1) were organized into arrays of $13 \times 10^{3}$ and $12 \times$ $10^{2}$ respectively. These spectra were pre-processed using the method of centering in the medium and then subjected to Partial Least Squares Regression (PLS) analysis in Unscrambler. For this PLS model, regions of the spectra of $1700-1800 \mathrm{~cm}^{-1}$ were selected, for representing the $\mathrm{C}=\mathrm{O}$ stretching vibration of ester groups.

\section{Results and Discussion}

Total fluorescence spectra and FTIR/ATR were reported for transesterification of soybean oil at different reaction times and for standard mixtures of triolein and methyl oleate. Knowing that during a transesterification reaction, the amounts of mono-, di- and triglycerides differ according to the reaction time, a PLS model was developed to monitor the reaction and evaluate the yield of methyl oleate, which is an ester derived from oleic acid. Table 1 shows the standard mixtures used in the PLS model proposed.

Figure 1 presents the graph of the predicted values relating to the reference values for the PLS model, which was built using the ATR/FTIR spectra in the region of $1700-1800 \mathrm{~cm}^{-1}$ as independent variables and the \% values of methyl oleate $(\mathrm{v} / \mathrm{v})$ as dependent variables. The region of $1700-1800 \mathrm{~cm}^{-1}$ was chosen as independent variables to be a spectral region belonging to the group of ester carbonyls thus serving as a key parameter for the differentiation of standard mixtures, which contained different amounts of triolein and methyl oleate (Table 1).

As can be seen in the PLS model, the points are distributed around the line of bisection, showing that there is no systematic error in the predictions. In other words, there was a good correlation of this model determined by FTIR/PLS, showing a correlation of 0.9941 and a coefficient of determination $\left(\mathrm{R}^{2}\right)$ of 0.9883 . This regression coefficient of the curve near to 1 indicates the efficiency of the model for making predictions. Thus, this PLS model served as reference model to determine the \% of methyl oleate in the samples collected from the transesterification reaction at different reaction times (Table 2). This FTIR/PLS model has also been chosen in this 


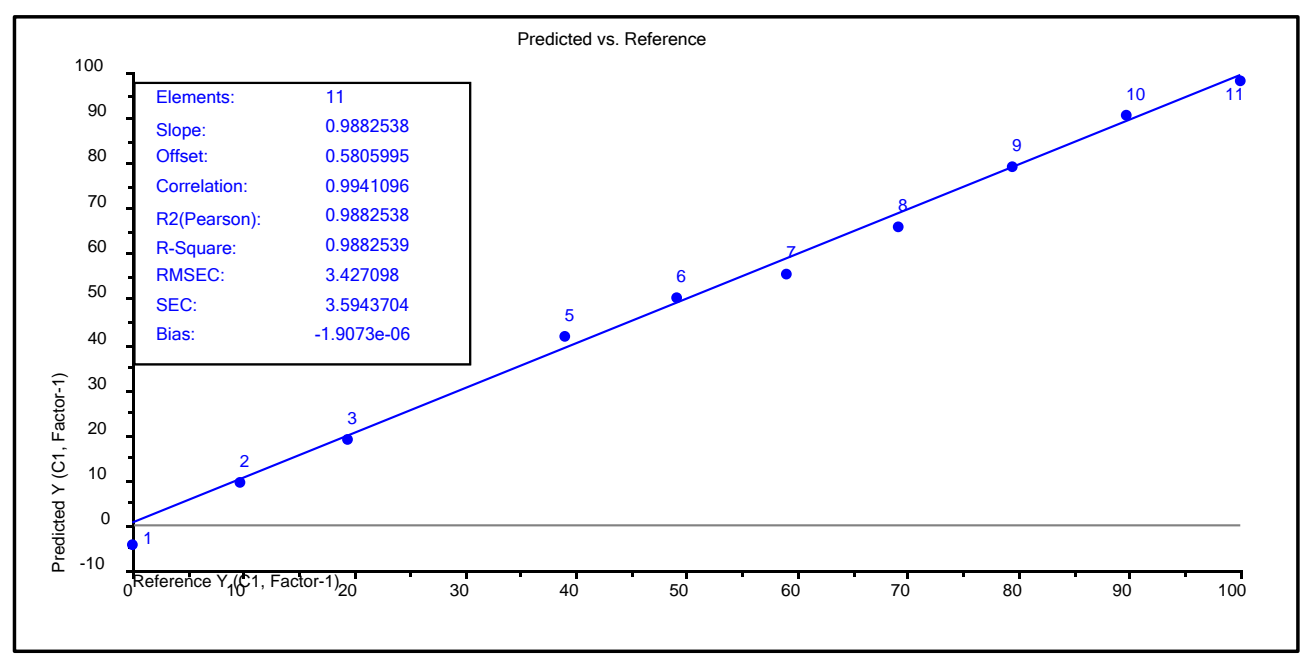

Figure 1. PLS model using the ATR-FTIR spectra in the region of $1700-1800 \mathrm{~cm}^{-1}$ as independent variables and the values of $\%$ of methyl oleate $(w / w)$ as dependent variables.

Table 2. Predictive capability based on the PLS regression of the FTIR data.

\begin{tabular}{ccc}
\hline Methyl oleate $(\mathbf{\%})(\mathbf{m} / \mathbf{m})$ & Triolein (\%) \\
\hline 0 & 0.8 \\
5 & 23.9 \\
10 & 40.3 \\
15 & 51.2 \\
20 & 56 \\
25 & 63.5 \\
30 & 68.2 \\
35 & 70.4 \\
40 & 74.3 \\
45 & 75.5 \\
50 & 77 \\
\hline
\end{tabular}

work as a reference method, for being a method for predicting the yield of reaction of biodiesel production already used in literature by Zagonel et al. [1].

From the concentrations of methyl oleate found by the reference method (ATR-TIR) in transesterificadas samples was built the new model PLS now relating the fluorescence spectra with concentrations (Figure 2, Table 2), where the fluorescence spectra appear as independent variables and the values of the $\%$ of methyl oleate $(\mathrm{v} / \mathrm{v})$ as the dependent variables. This model was significant, and also showed a good correlation of the same determined by fluorimetry/PLS, presenting an $\mathrm{R}^{2}$ close to 1 , with a value of 0.9836 .

In general, the proposed method (association between spectrofluorimetry and PLS) was efficient for monitoring the transesterification of soybean oil, which is quite reliable for predicting the yield of esters in the course of transesterification reactions.

\section{Conclusion}

The association between spectrofluorimetry and PLS proved to be a rapid, nondestructive, inexpensive, efficient, 


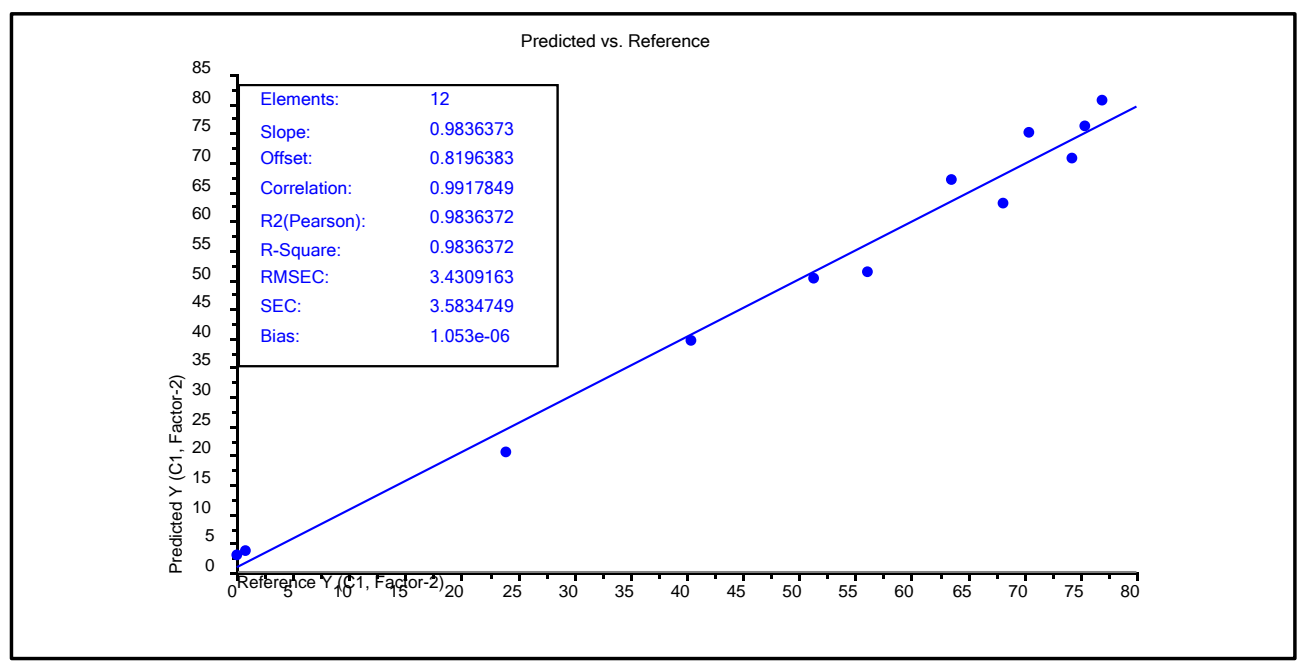

Figure 2. PLS model using the fluorescence spectra as independent variables and the values of the \% of methyl oleate $(\mathrm{w} / \mathrm{w})$ as dependent variables.

and accurate method for monitoring the transesterification of soybean oil, and contributed much to the analysis and interpretation of analytical data.

\section{Acknowledgements}

Capes, CNPq, Fapesb.

\section{References}

[1] Zagonel, G.F., Peralta-Zamora, P. and Ramos, L.P. (2004) Multivariate Monitoring of Soybean Oil Ethanolysis by FTIR. Talanta, 63, 1021-1025. http://dx.doi.org/10.1016/j.talanta.2004.01.008

[2] Quintella, C.M., Teixeira, L.S.G., Korn, M.G.A., Costa Neto, P.R., Torres, E.A., Castro, M.P. and Jesus, C.A.C. (2009) Cadeia do biodiesel da bancada à indústria: Uma visão geral com prospecção de tarefas e oportunidades para P\&D\&I. Quimica Nova, 32, 793-808. http://dx.doi.org/10.1590/S0100-40422009000300022

[3] Board, N.B. (1998) Anais do Congresso Internacional de Biocombustíveis Líquidos. Secretária de Estado da Ciência: Curitiba.

[4] Schuchardt, U., Sercheli, R. and Vargas, R.M. (1998) Transesterification of Vegetable Oils: A Review. Journal of the Brazilian Chemical Society, 9, 199-210. http://dx.doi.org/10.1590/S0103-50531998000300002

[5] Mittebach, M., Roth, G. and Bergmann, A. (1996) Simultaneous Gas Chromatographic Determination of Methanol and Free Glycerol in Biodiesel. Chromatographia, 42, 431-434. http://dx.doi.org/10.1007/BF02272135

[6] Trathnigg, B. and Mittelbach, M. (1990) Analysis of Triglyceride Methanolysis Mixtures Using Isocratic HPLC with Density Detection. Journal of Liquid Chromatography, 13, 95-105. http://dx.doi.org/10.1080/01483919008051790

[7] Gelbard, G., Brès, O., Vargas, R.M., Vielfaure, F. and Schuchardt, U.F. (1995) 1H Nuclear Magnetic Resonance Determination of the Yield of the Transesterification of Rapeseed Oil with Methanol. Journal of the American Oil Chemists' Society, 72, 1239-1241.

[8] Ellis, N., Guan, F., Chen, T. and Poon, C. (2008) Monitoring Biodiesel Production (Transesterification) Using in Situ Viscometer. Chemical Engineering Journal, 138, 200-206. http://dx.doi.org/10.1016/j.cej.2007.06.034

[9] Sikora, Z. and Salacki, W. (1996) Use of Near-Infrared (NIR) Spectroscopy to Predict Several Physical and Operating Properties of Oil Fractions and Diesel Fuel. Petroleum and Coal, 38, 65-68.

[10] Arzamendi, G., Arguiñarena, E., Campo, I. and Gandía, L.M. (2006) Monitoring of Biodiesel Production: Simultaneous Analysis of the Transesterification Products Using Size-Exclusion Chromatography. Chemical Engineering Journal, 122, 31-40. http://dx.doi.org/10.1016/j.cej.2006.05.009

[11] Bulent Koc, A. (2009) Ultrasonic Monitoring of Glycerol Settling during Transesterification of Soybean Oil. Bioresource Technology, 100, 19-24. http://dx.doi.org/10.1016/j.biortech.2008.05.037

[12] Gerhard, K. (2000) Monitoring a Progressing Transesterification Reaction by Fiber-Optic near Infrared Spectroscopy with Correlation to 1H Nuclear Magnetic Resonance Spectroscopy. Journal of the American Oil Chemists' Society, 77, 
489-493.

[13] Meira, M., Quintella, C.M., Tanajura, A.S., da Silva, H.R.G., D’Erasmo Santos Fernando, J., Netoc, P.R.C., Pepe, I.M., Santos, M.A. and Nascimento, L.L. (2011) Determination of the Oxidation Stability of Biodiesel and Oils by Spectrofluorimetry and Multivariate Calibration. Talanta, 85, 430-434. http://dx.doi.org/10.1016/j.talanta.2011.04.002

[14] Guimarães, A.K., Quintella, C.M. and Musse, A.P. (2006) Prêmio Petrobras de tecnologia. http://sites.petrobras.com.br/minisite/premiotecnologia/index.asp

[15] Meira, M., Quintella, C.M., Ferrer, T.M., Silva, H.R.G., Guimarães, A.K. and Santos, M.A. (2011) Identificação de adulteração de biocombustível por adição de óleo residual ao diesel por espectrofluorimetria total 3D e análise das componentes principais. Quimica Nova, 34, 621-624. http://dx.doi.org/10.1590/S0100-40422011000400013

[16] Lima, A.L., Lima, A.P., Portela, F.M., Santos, D.Q., Neto, W.B., Hernández-Terrones, M.G. and Fabris, J.D. (2010) Parâmetros da reação de transesterificação etílica com óleo de milho para produção de biodiesel. Eclética Química, 35, 101-106. http://dx.doi.org/10.1590/S0100-46702010000400013 